\title{
Yem Bezelyesi (Pisum sativum ssp. arvense L.) Genotiplerine Ait Tohumların Bazı Fiziksel ve Fizyolojik Özelliklerinin Belirlenmesi Üzerine Bir Araştırma
}

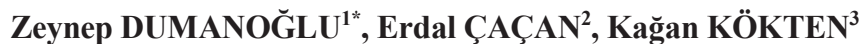 \\ ${ }^{\prime}$ Bingöl Üniversitesi, Ziraat Fakültesi, Biyosistem Mühendisliği Bölümü, Bingöl, TÜRKIYE \\ ${ }^{2}$ Bingöl Üniversitesi, Gıda, Tarlm ve Hayvancllk Meslek Yüksekokulu, Bitkisel ve Hayvansal Üretim Bölümü, Bingöl, TÜRKIYE \\ ${ }^{3}$ Bingöl Üniversitesi, Ziraat Fakültesi, Tarla Bitkileri Bölümü, Bingöl, TÜRKIYE
}

\begin{tabular}{|c|c|}
\hline Geliş Tarihi/Received: 15.10 .2021 & Kabul Tarihi/Accepted: 06.12.2021 \\
\hline \multicolumn{2}{|l|}{ ORCID ID (Yazar sirasina göre / by author order) } \\
\hline (1) orcid.org/0000-0002-7889-9015 (1Dorcid.org/0000-0002-94 & cid.org/0000-0001-5403-5629 \\
\hline
\end{tabular}

"Sorumlu Yazar/Corresponding Author: zdumanoglu@bingol.edu.tr

Öz: $\mathrm{Bu}$ araştırma, yem bezelyesi (Pisum sativum ssp. arvense L.) genotiplerine ait tohumların fiziksel ve fizyolojik özelliklerinin belirlenmesi ve genotiplerin bu özellikler açısından karşılaştırılması amacıyla 2019-2020 y1llarında Bingöl Üniversitesi Ziraat Fakültesi laboratuvarlarında yürütülmüştür. Materyal olarak, yem bezelyesinin Creakerjack, Kristal, Özkaynak, Servet, Taşkent ve TTAE-YB2010 genotiplerine ait tohumlar kullanılmıştır. Bu tohumlara ait fiziksel özelliklerden uzunluk, genişlik, yüzey alanı, ortalama aritmetik çap ve bin tane ağırlığı; fizyolojik özelliklerden ise çimlenme oranı, çimlenme zamanı ve ortalama sürgün uzunluğu ele alınmıştır. Araştırmada yem bezelyesi tohumlarının ortalama $6.730 \mathrm{~mm}$ uzunluk, $6.118 \mathrm{~mm}$ genişlik, $34.117 \mathrm{~mm}^{2}$ yüzey alanı, $6.424 \mathrm{~mm}$ aritmetik çap ve $191.96 \mathrm{~g}$ bin tane ağırlığına sahip olduğu belirlenmiştir. Yem bezelyesi tohumlarının ortalama 1.335 gün içerisinde çimlendikleri, çimlenme oranının ortalama \% 99.5 olduğu ve ortalama sürgün uzunluğunun da $4.775 \mathrm{~cm}$ olduğu saptanmıștır. Araștırma neticesinde fiziksel özellikler açısından Kristal, fizyolojik özellikler açısından ise Özkaynak çeşidinin iyi sonuçlar verdiği belirlenmiştir.

Anahtar Kelimeler: Pisum sativum ssp. arvense L., yem bitkisi, tohum boyutları, tohum özellikleri, fizyolojik özellikler

\section{A Research on the Determination of Some Physical and Physiological Characteristics of Seeds of Forage Pea (Pisum sativum ssp. arvense L.) Genotypes}

\begin{abstract}
This research was carried out to determine the physical and physiological characteristics of the seeds of the forage pea (Pisum sativum ssp. arvense L.) genotypes, and to compare the genotypes in terms of these characteristics in the laboratories of the Faculty of Agriculture of Bingöl University in 2019-2020. As a material, seeds belonging to Creakerjack, Kristal, Özkaynak, Servet, Taşkent, and TTAE-YB2010 genotypes of forage peas were used. Length, width, surface area, average arithmetic diameter, and thousand-grain weight from physical properties of these seeds, germination rate, germination time, and average shoot length from physiological properties were taken into consideration. In the study, it was determined that forage pea seeds had an average length of $6.730 \mathrm{~mm}$, a width of $6.118 \mathrm{~mm}$, a surface area of $34.117 \mathrm{~mm}^{2}$, an arithmetic diameter of 6.424 $\mathrm{mm}$, and a thousand-grain weight of $191.96 \mathrm{~g}$. It was determined that forage pea seeds germinated in an average of 1,335 days, the average germination rate was $99.5 \%$ and the average shoot length was $4.775 \mathrm{~cm}$. As a result of the research, it was determined that the Kristal variety gave good results in terms of physical properties and the Özkaynak variety in terms of physiological properties.
\end{abstract}

Keywords: Pisum sativum ssp. arvense L., forage crops, seed size, seed characteristics, physiological properties 


\section{Giriş}

Yem bezelyesi (Pisum sativum ssp. arvense L.) adaptasyon yeteneği yüksek, fazla azotlu gübre kullanımını istemeyen, toprağa azot bağlayabilen, kendinden sonra gelen bitkiler için temiz bir tarla bırakan ve verimi yüksek önemli bir yem bitkisidir (Timurağaoğlu ve ark., 2004; Uzun ve ark., 2012; Kadıŏlu ve Tan, 2018a; Temel ve Yazıcı, 2021).

Tek y1llk ve serin mevsim yem bitkisi olan yem bezelyesi, ot, tane yemi, silaj, mera ve yeşil gübre bitkisi olarak kullanılmakta (Manga ve ark., 2003; Acikbas ve ark., 2021); tohum üretimi, hem üretim materyali ihtiyacını hem de hayvanların kesif yem ihtiyacını karşılamak için yapılmaktadır (Sayar, 2021). Protein oranının yüksekliğinden dolayı yem bezelyesi tohumları kıymetli kesif yem kaynağıdır (Avcıŏglu ve ark., 2009).

Bitkiler, yetiştirildikleri ortam (iklim, coğrafya) ve toprak özelliklerine ( $\mathrm{pH}$, tuzluluk vb.) bağlı olarak benzer genotip özelliklerine sahip olsalar da, farklı gelişim gösterebilmektedirler. Bu durum doğal olarak oluşturdukları tohumlara da yansımaktadır (Dumanoğlu ve ark., 2021). Tohum araştırmalarında, ıslah çalışmalarında ve mekanizasyon uygulamalarında tohumlara ait temel özelliklerden faydalanılmaktadır (Dumanoğlu, 2021).

Yem bezelyesi ile ilgili olarak yapılan çalışmalara bakıldığında, bu çalışmaların daha çok yem verimi ve kalitesi (Kadığlu ve Tan, 2018b; Konuk ve Tamkoç, 2018; Çaçan ve ark., 2019; Keskin ve ark., 2021) üzerinde yoğunlaştığı görülmektedir. Yem bezelyesinin tohum özelliklerinin incelendiği çalıșmalarda da genel olarak çimlenme özellikleri (Çaçan ve ark., 2016; Açıkbaş ve Özyazıc1, 2021; Uslu ve ark., 2021) ve bin tane ağırlıkları (Uzun ve ark., 2012; Seydoşoğlu, 2013; Konuk ve Tamkoç, 2018; Sürmen ve ark., 2019) gibi parametreler öne çıkmaktadır. Ancak yem bezelyesi tohumlarının fiziksel ve fizyolojik özellikleri üzerine yapılan çalışmalar yok denecek kadar az sayıdadır.

$\mathrm{Bu}$ çalışma, yem bezelyesi ( $P$. sativum ssp. arvense L.) tohumlarının fiziksel ve fizyolojik özelliklerinin belirlenmesi amacıyla yürütülmüştür. Araştırma sonunda elde edilen verilerin, yem bezelyesi ile ilgili 1slah, mekanizasyon ve tohum teknolojisi konularında çalışan bilim insanlarına ve üreticilere fayda sağlayacağı ön görülmektedir.

\section{Materyal ve Yöntem}

Bu çalışma; 2019-2020 yıllarında, Bingöl Üniversitesi Ziraat Fakültesi Biyosistem Mühendisliği ve Tarla Bitkileri bölümlerine ait laboratuvarlarda yürütülmüştür. Çalışmada, altı farkl1 yem bezelyesi (P. sativum ssp. arvense L.) genotipi (Creakerjack, Kristal, Özkaynak, Servet, Taşkent ve TTAE-YB2010)'ne ait tohumların bazı fiziksel (uzunluk, genişlik, yüzey alanı, ortalama aritmetik çap, bin tane ağırlığı) ve fizyolojik özellikleri (çimlenme oranı, çimlenme zamanı ve ortalama sürgün uzunluğu) belirlenmiştir. Çalışmada, kontrollü şartlar altında $\left(+4{ }^{\circ} \mathrm{C}\right.$, buzdolabında, karanlık ortamda, cam kavanozların içerisinde) muhafaza edilen yem bezelyesi genotiplerine ait tohumlar kullanılmıştır.

Tohumların; uzunluk ( $\mathrm{mm})$, genişlik ( $\mathrm{mm})$ ve yüzey alanları $\left(\mathrm{mm}^{2}\right)$, kendisine ait yazılımı olan bir stereo mikroskop (Nikon SMZ 745T) ile ölçülmüştür (Dumanoğlu ve Geren, 2020; Dumanoğlu ve Ekren, 2021). Buradan elde edilen verilerden faydalanılarak tohumlara ait ortalama aritmetik çap (D) (mm) değerleri Eşitlik 1'e göre saptanmıştır (Mohsenin, 1970; Alayunt, 2000; Kara, 2012).

$$
D=(L+W) / 2
$$

Eşitlikte $L$, tohuma ait uzunluk değerini (mm); $W$, tohuma ait genişlik değerini (mm) ifade etmektedir.

Tohumların, geometrik ve şekil özelliklerine göre sinıflandirılmasinda Tablo 1'de verilen değerler kullanılmıştır. Tohumlara ait bin tane ağırlıkları (g) ise rastgele olacak şekilde örneklenmiş ve üçer tekrarlı olacak şekilde saptanmıştır (Dumanoğlu ve Öztürk, 2021).

Yem bezelyesi tohumlarının bazı fizyolojik özelliklerini belirlemek amaciyla tohumlar, Anonymous (2007) kurallarına göre kontrollü şartlar altında $\left(20-25{ }^{\circ} \mathrm{C}\right.$ ve $\% 60$ nem, karanlık ortam, cam petri içerisinde) BINDER marka inkübatör içerisinde 8 günde çimlendirilmiştir. Laboratuvar denemesi, tesadüf parselleri deneme desenine göre dört tekrarlı olacak şekilde

Tablo 1. Tohumların geometrik ve șekil özelliklerine göre sınıflandırılması (Yağcıoğlu, 2015) Table 1. Classification of seeds according to geometric and shape characteristics (Yağcioğlu, 2015)

\begin{tabular}{cccc}
\hline $\begin{array}{c}\text { Geometrik özelliklerine } \\
\text { göre tohumlar }\end{array}$ & $\begin{array}{c}\text { Tane genişliği/tane uzunluğu } \\
\text { (b/a) }(\mathrm{mm})\end{array}$ & $\begin{array}{c}\text { Şekil özelliklerine } \\
\text { göre tohumlar }\end{array}$ & $\begin{array}{c}\text { Uzunluk }(\mathrm{a}), \text { genişlik (b), } \\
\text { kalınllk }(\mathrm{c})(\mathrm{mm})\end{array}$ \\
\hline Uzun & $<0.6$ & Yuvarlak & $\mathrm{a} \approx \mathrm{b} \approx \mathrm{c}$ \\
Orta & $0.6-0.7$ & Oval & $\mathrm{a} / 3<\mathrm{b} \approx \mathrm{c}$ \\
Kısa & $>0.7$ & Uzun & $\mathrm{c}<\mathrm{b}<\mathrm{a} / 3$ \\
\hline
\end{tabular}


kurulmuştur. Genotiplerin, çimlenme zamanı ve oranı günlük sayım yapılarak belirlenmiştir. Ayrıca, her bir tohum çeşidinden çimlenen tohumlar içerisinden rastgele 25 'er adet olmak üzere dörder tekrarlı örnekler alınmış ve ortalama sürgün uzunlukları $(\mathrm{cm})$ cetvel yardımı ile ölçülmüştür [Çimlendirme işlemlerinin tamamı aynı saat aralığında (10.00-12.00), 8. günde ve tek bir seferde tamamlanmıştır].

Elde edilen sonuçların, SPSS v.22 (Anonymous, 2013) istatistik paket programı kullanılarak tesadüf parselleri deneme desenine göre $p<0.05$ önemlilik düzeyinde varyans analizleri yapılmış; ortalamalar arasındaki farklılıklar, Tukey testi ile kontrol edilmiştir.

\section{Bulgular ve Tartışma}

\subsection{Yem bezelyesi tohumlarına ait bazı fiziksel özellikler}

Çalışmada, yem bezelyesi ( $P$. sativum ssp. arvense L.) genotipleri tohumlarına ait belirlenen fiziksel özelliklerden; uzunluk (mm), genişlik $(\mathrm{mm})$, yüzey alanı $\left(\mathrm{mm}^{2}\right)$, ortalama aritmetik çap $(\mathrm{mm})$ ve bin tane ağırlıkları $\mathrm{p}<0.05$ önemlilik düzeyinde Tablo 2'de verilmiştir.

Elde edilen verilere göre; yem bezelyesi tohumlarının uzunluk değerlerinin $5.463 \mathrm{~mm}$ ile $7.730 \mathrm{~mm}$ arasında değişim gösterdiği ve Crekerjack ile Kristal çeşitlerinin en yüksek uzunluk değerlerine (7.590 mm ve $7.730 \mathrm{~mm}$ ), Taşkent çeşidinin ise en düşük uzunluk (5.463 $\mathrm{mm}$ ) değerine sahip olduğu saptanmıştır. Yem bezelyesi genotipleri arasında en yüksek genişlik değeri $7.022 \mathrm{~mm}$ ile Kristal çeşidinden, en düşük değer ise $5.179 \mathrm{~mm}$ ile Taşkent çeşidinden elde edilmiştir. En yüksek yüzey alanı $45.038 \mathrm{~mm}^{2}$ ile Kristal çeşidinde belirlenirken, en düşük yüzey alanına ise $22.768 \mathrm{~mm}^{2}$ Taşkent çeşidine ait tohumlar sahip olmuştur. Tohumlara ait en yüksek aritmetik çap Kristal çeşidinde (7.376 mm), en düşük aritmetik çap ise Taşkent çeşidinde (5.321 mm) ölçülmüştür (Tablo 2). Tablo 1'de belirtilen sınıflandırma değerlerine göre, incelenen yem bezelyesi genotiplerine ait tohumların kısa ve oval bir forma sahip olduğu belirlenmiştir. Elde edilen bu verilere göre özellikle tarımsal mekanizasyon uygulamalarında tohumların yapısına bağlı olarak öncelikle ekici düzen, devamında da buna bağlı olarak uygun alet, makine ve sistemler belirlenebilecektir.

Yem bezelyesi tohumlarının bin tane ağırlıkları 112.57-266.40 g arasında değişim göstermiştir. En yüksek bin tane ağırlığının Crekerjack ve Kristal çeşitlerinden elde edildiği görülmektedir (Tablo 2). Tohumlara ait bin tane ağırlıklarının belirlenmesi, üreticiler açısından tohum israfının önlenmesi ve yeterli miktarda tohum alımı yapılarak girdi masraflarından tasarruf sağlanması açısından son derece önemlidir.

Elde edilen veriler, Avcıŏlu ve Geren (1997)'in yem bezelyesi ile ilgili olarak belirtmiş oldukları tohumlarının boyutları (5-6 mm çap) ve bin tane ağırlıkları (130-240 g ila 400-500g) ile uyum içerisinde olduğu görülmüştür. Ortalama $191.96 \mathrm{~g}$ olarak elde edilen bin tane ağırlığının aynı zamanda Uzun ve ark. (2012) tarafindan elde edilen bulgular (167-193 g) ile de benzerlik gösterdiği saptanmıştır. Giresun ilinde yerel bezelyelerle yürütülen bir çalışmada tohum kabuğu yüzeylerinin düz, tohum şekillerinin ticari çeşitlerde yuvarlak, yerel çeşitlerde köşeli ve yuvarlak olarak farklılık gösterdiği; tohum boyunun 5.77-12.20 mm, tohum genişliğinin 5.60$11.78 \mathrm{~mm}$ ve bin tane ağırlığının 128.39-243.82 g arasında değiștiği bildirilmiştir (Kılınç, 2017). Bu sonuçların da çalışma bulguları ile benzerlik gösterdiği görülmektedir.

\subsection{Yem bezelyesi tohumlarina ait bazı fizyolojik özellikler}

$\mathrm{Bu}$ araştırmada, altı farklı yem bezelyesi $(P$. sativum ssp. arvense L.) genotiplerine ait tohumların fizyolojik özelliklerden çimlenme

Tablo 2. Yem bezelyesi tohumlarına ait bazı fiziksel özellikler*

Table 2. Some physical properties of the forage pea seeds*

\begin{tabular}{lccccc}
\hline $\begin{array}{l}\text { Yem bezelyesi } \\
\text { genotipleri }\end{array}$ & $\begin{array}{c}\text { Uzunluk } \\
(\mathrm{mm})\end{array}$ & $\begin{array}{c}\text { Genişlik } \\
(\mathrm{mm})\end{array}$ & $\begin{array}{c}\text { Yüzey alanı } \\
\left(\mathrm{mm}^{2}\right)\end{array}$ & $\begin{array}{c}\text { Ortalama aritmetik } \\
\text { çap }(\mathrm{mm})\end{array}$ & $\begin{array}{c}\text { Bin tane ağırlı̆̆ı } \\
(\mathrm{g})\end{array}$ \\
\hline Crekerjack & $7.590^{\mathrm{a}}$ & $6.799^{\mathrm{b}}$ & $42.265^{\mathrm{b}}$ & $7.195^{\mathrm{b}}$ & 266.40 \\
Kristal & $7.730^{\mathrm{a}}$ & $7.022^{\mathrm{a}}$ & $45.038^{\mathrm{a}}$ & $7.376^{\mathrm{a}}$ & 262.70 \\
Özkaynak & $5.612^{\mathrm{d}}$ & $5.258^{\mathrm{e}}$ & $24.018^{\mathrm{e}}$ & $5.435^{\mathrm{e}}$ & 112.57 \\
Servet & $7.364^{\mathrm{b}}$ & $6.331^{\mathrm{c}}$ & $37.762^{\mathrm{c}}$ & $6.847^{\mathrm{c}}$ & 207.17 \\
Taşkent & $5.463^{\mathrm{d}}$ & $5.179^{\mathrm{e}}$ & $22.768^{\mathrm{e}}$ & $5.321^{\mathrm{e}}$ & 115.77 \\
TTAE-YB2010 & $6.623^{\mathrm{c}}$ & $6.116^{\mathrm{d}}$ & $32.851^{\mathrm{d}}$ & $6.370^{\mathrm{d}}$ & 187.13 \\
\hline Ortalama & 6.730 & 6.118 & 34.117 & 6.424 & 191.96 \\
\hline Standart sapma & 1.001 & 0.768 & 9.288 & 0.881 & 6.769 \\
\hline
\end{tabular}

": Aynı sütunda aynı harfle gösterilen ortalamalar arasındaki farklılık istatistiki açıdan önemli değildir. 
zamanı (gün), çimlenme oranı (\%) ve ortalama sürgün uzunluğu $(\mathrm{cm})$ Tablo 3 'te verilmiştir. Yem bezelyesi tohumlarının çimlenme zamanı 1.2521.395 gün arasında değişmiştir. İstatistiksel olarak farklılık olmamakla beraber, çimlendirme çalışmasına göre en erken çimlenen Özkaynak çeşidi olurken, en geç çimlenen Crekerjack çeşidi olmuştur. Tüm yem bezelyesi çeşitleri ortalama 1.335 gün içerisinde çimlenmiştir. Çimlenme oranı sadece Crekerjack çeşidinde \% 97 olarak belirlenmiştir. Diğer çeşitlere ait tohumların ise, tamamı çimlenmiştir. Ortalama sürgün uzunluğu $1.806-7.495 \mathrm{~cm}$ arasında değişmiş olup; en düşük sürgün uzunluğunu Crekerjack çeşidi verirken, en yüksek sürgün uzunluğunu Özkaynak çeşidi vermiştir. Tüm genotiplerin ortalama sürgün uzunluğu $4.775 \mathrm{~cm}$ olarak tespit edilmiştir (Tablo 3). Hayvansal üretimde değerlendirilen bir bitki olan yem bezelyesine ait elde edilen bazı fizyolojik değerler, üreticiler tarafından özellikle tarımsal arazilerin erozyon kontrolü (kök uzunlukları) ve yem kalitesi açısından (sürgün uzunlukları) değerlendirme olanağı sağlamaktadır. Ayrıca, bilim insanlarının bu değerleri göz önüne alarak ıslah ve arazi çalışmalarından genotip tercihi yapmaları bakımından faydalı olacaktır.

Tablo 3. Yem bezelyesi tohumlarına ait bazı fizyolojik özellikler

Table 3. Some physiological properties of forage pea seeds

\begin{tabular}{lccc}
\hline $\begin{array}{l}\text { Yem bezelyesi } \\
\text { genotipleri }\end{array}$ & $\begin{array}{c}\text { Çimlenme } \\
\text { zamanı } \\
\text { (gün) }\end{array}$ & $\begin{array}{c}\text { Çimlenme } \\
\text { oranı } \\
(\%)\end{array}$ & $\begin{array}{c}\text { Ortalama sürgün } \\
\text { uzunluğu } \\
(\mathrm{cm})\end{array}$ \\
\hline Crekerjack & 1.395 & 97.0 & 1.806 \\
Kristal & 1.363 & 100.0 & 5.493 \\
Özkaynak & 1.252 & 100.0 & 7.495 \\
Servet & 1.361 & 100.0 & 4.025 \\
Taşkent & 1.286 & 100.0 & 5.600 \\
TTAE-YB2010 & 1.352 & 100.0 & 4.231 \\
\hline Ortalama & 1.335 & 99.5 & 4.775 \\
\hline Standart sapma & 0.054 & 1.225 & 1.911 \\
\hline
\end{tabular}

Çaçan ve ark. (2016) bazı yem bezelyesi hat ve çeşitlerin (88P038-4-3-683, Spring pea 3-638, P57B, P51, P101, P104 ve P57K hatlar1 ile Atos, Özkaynak, Reyna, Ultrillo, Spring ve Bolero çeşitleri), farklı sıcaklık değerlerinde çimlenme ve çıkış performanslarını belirledikleri çalışmalarında; Özkaynak çeşidinin 20-25 ${ }^{\circ} \mathrm{C}$ sıcaklık aralığında \% 90-95 oranında, 2.35-3.00 gün süre ile çimlendiğini rapor etmişlerdir.

\section{Sonuçlar}

Bu araştırmada, altı farklı yem bezelyesi ( $P$. sativum ssp. arvense L.) genotipine ait tohumların bazı fiziksel ve fizyolojik özellikleri belirlenmiştir. Elde edilen sonuçlara göre bu çalışmada incelenen yem bezelyesi genotiplerine ait tohumların kısa ve oval bir forma sahip oldukları saptanmıştır. Fiziksel özellikler açısından Kristal, fizyolojik özellikler açısından ise Özkaynak çeşidi üstün özellikler göstermiştir. Belirlenen fiziksel özellikler, özellikle tarımsal mekanizasyon uygulamalarında ekim işlemi için seçilecek uygun alet, makine ve sistemlerinin belirlenmesinde, tohum yapılarına göre seçilen ekici ünitelerin saptanarak ikizlenme ve tohum kaybı en az düzeyde olacak şekilde ekim işleminin gerçekleşmesine olanak sağlamaktadır. Bu özellikler 1slah çalışmalarında genotip farklılıklarının karşılaştırmalı olarak ortaya konmasına ve üzerinde çalışılacak genotipin belirlenmesinde araştırmacılara yardımcı olmaktadır. Diğer yandan, tohum teknolojisi bakımından hormon, gübre ya da ilaç uygulamalarının tohumlara uygulanması aşamasında yine bu verilerden faydalanma olanağ bulunmaktadır. Çalışmada, yem bezelyesi genotipleri ile ilgili incelenen bazı fizyolojik özellikler sonucunda elde edilen veriler yardımı ile diğer genotiplere göre daha kısa süre içerisinde çimlenme yeteneğine sahip ve sürgün uzunluğu yüksek olan genotipler belirlenmiştir. Bu özellikler genotiplerin tarımsal arazilerde değerlendirilme olasılığ́ ve hayvanların kısa sürede uzun sürgün veren genotipleri tercih etmesi açısından önem arz etmektedir.

\section{Kaynaklar}

Acikbas, S., Ozyazici, M.A., Bektas, H., 2021. The effect of salinity on root architecture in forage pea (Pisum sativum ssp. arvense L.). Legume Research, 44(4): 407-412.

Açıkbaş, S., Özyazıcı, M.A., 2021. Silisyum tohum ön uygulamasinin tuz stresine maruz birakilan yem bezelyesi [Pisum sativum ssp arvense (L.) Poir]'nin çimlenme gelişimine etkisi. Middle East International Conference on Contemporary Scientific Studies-V, 27-28 March, Ankara, Vol. III, pp. 148-158.

Alayunt, F.N., 2000. Biyolojik Malzeme Bilgisi. Ege Üniversitesi Ziraat Fakültesi, Tarım Makineleri Bölümü Ders Kitabı, Ege Üniversitesi, Ziraat Fakültesi Yayınları No: 541, Bornova-İzmir.

Anonymous, 2007. Seed Germination Testing Rules. International Seed Testing Association (ISTA).

Anonymous, 2013. IBM SPSS Statistics for Windows, Version 22.0. Armonk, NY: IBM Corp.

Avcioğlu, R., Geren, H., 1997. Yem Bitkileri. Hasat Yayınc1lik, İstanbul.

Avcioğlu, R., Hatipoğlu, R., Karadağ, Y., 2009. Yem Bitkileri: Baklagil Yem Bitkileri. Cilt II, Tarım ve Köyişleri Bakanlığı, Tarımsal Üretim ve Geliştirme Genel Müdürlüğü, İzmir.

Çaçan, E., Kökten, K., Bakoğlu, A., Kaplan, M., 
Bozkurt, A., 2019. Bazı yem bezelyesi hat ve çeşitlerinin (Pisum arvense L.) ot verimi ve kalitesi açısından değerlendirilmesi. Harran Tarım ve Gıda Bilimleri Dergisi, 23(3): 254-262.

Çaçan, E., Özbay, N., Kökten, K., 2016. Bazı yem bezelyesi hat ve çeşitlerinin farklı sıcaklıklarda çimlenme ve çıkış performanslarının belirlenmesi. Nevşehir Bilim ve Teknoloji Dergisi, 5(Özel sayı): 62-68.

Dumanoğlu, Z., 2021. A study on determination of some physical and physiological properties seeds of seeds of two different jute varieties (Corchorus capsularis L. and Corchorus olitorius L.). ISPEC Journal of Agricultural Sciences, 5(2): 456-462.

Dumanoğlu, Z., Çaçan, E., Kökten K., 2021. Korunga (Onobrychis viciifolia Scop.) genotiplerine ait tohumların fiziksel özelliklerinin belirlenmesi. Journal of Anatolian Environmental and Animal Sciences, 6(1): 18-24.

Dumanoğlu, Z., Ekren, S., 2021. A research on determination of some physical and physiological properties of tobacco seeds (Nicotiana tabacum L.) from different harvest years. $3^{\text {rd }}$ International Conference on Food, Agriculture and Veterinary, 1920 June, İzmir, pp. 1260-1266.

Dumanoğlu, Z., Geren, H., 2020. An investigation on determination of seed characteristics of some glutenfree crops (Amarantus mantegazzianus, Chenopodium quinoa Willd., Eragrostis tef [Zucc] Trotter, Salvia hispanica L.). Turkish Journal of Agriculture-Food Science and Technology, 8(8): 1650-1655.

Dumanoğlu, Z., Öztürk, G., 2021. A research on improving seed quality (pelleting) in true potato of 101(Nif) genotype. Fresenius Enviromental Bulletin, 30: 10983-10988

Kadığlu, S., Tan, M., 2018a. Erzurum şartlarında bazı yem bezelyesi hat ve çeşitlerinin tohum verimleri ile bazı özelliklerinin belirlenmesi. Atatürk Üniversitesi Ziraat Fakültesi Dergisi, 49(2): 143-149.

Kadıoğlu, S., Tan, M., 2018b. Erzurum şartlarında farklı tarihlerde kışlık ekilen yem bezelyesi çeşitlerinin verim ve bazı özellikleri. Tarla Bitkileri Merkez Araştırma Enstitüsü Dergisi, 27(1): 25-32.

Kara, M., 2012. Biyolojik Ürünlerin Fiziksel Özellikleri. Atatürk Üniversitesi, Ziraat Fakültesi Yayınları No: 242, Erzurum.

Keskin, B., Temel, S., Eren, B., 2021. Farklı zamanlarda ekilen bazı yem bezelyesi (Pisum sativum ssp. arvense L.) çeşitlerinin tohum ve kesinin besin değerleri. Uluslararası Tarım ve Yaban Hayatı Bilimleri Dergisi, 7(1): 96-105.
Kılınç, H.V., 2017. Giresun ilinde yetişen yerel bezelye (Pisum sativum L.) populasyonlarını morfolojik karekterizasyonunun belirlenmesi. Yüksek lisans tezi, Ordu Üniversitesi, Fen Bilimleri Enstitüsü, Ordu.

Konuk, A., Tamkoç, A., 2018. Yem bezelyesinde kışlık ve yazlık ekimin bazı tarımsal özellikler üzerine etkisi. Bahri Dağdaş Bitkisel Araştırma Dergisi, 7(1): 39-50.

Manga, İ., Acar, Z., Ayan, İ., 2003. Baklagil Yembitkileri. Ondokuz Mayis Üniversitesi, Ziraat Fakültesi, Ders Kitabı No: 7, (Genișletilmiş II. Bask1), Samsun.

Mohsenin, N.N., 1970. Physical Properties of Plant and Animal Materials. Gordon and Breach Science Publishers, New York.

Sayar, M.S., 2021. Yem bezelyesi tarımı ve GAP Pembesi yem bezelyesi çeşidinin önemli tarımsal özellikleri. Dicle Üniversitesi Fen Bilimleri Enstitüsü Dergisi, 10(1): 73-82.

Seydoşoğlu, S., 2013. Diyarbakır ekolojik koşullarında baz1 yem bezelyesi (Pisum sativum L.) genotiplerinin verim ve verim unsurları. Türk Doğa ve Fen Dergisi, 2(2): 21-27.

Sürmen, M., Kara, E., Erdoğan, H., 2019. Farklı yem bezelyesi (Pisum sativum ssp. arvense L.) ve yaygin fiğ (Vicia sativa L.) çeşitlerinin Aydın ekolojisinde tohum verim özellikleri. International Congress on Agriculture and Forestry Research, 8-10 April, Marmaris/Turkey, p. 1318-1327.

Temel, S., Yazıcı, E., 2021. Ağrı-Eleşkirt koşullarında yazlık olarak farklı zamanlarda ekilen yem bezelyesi çeșitlerinin ot verimi ve bazı kalite özelliklerinin belirlenmesi. Uluslararası Tarm ve Yaban Hayatı Bilimleri Dergisi, 7(2): 306-314.

Timurağaoğlu, K.A., Genç, A., Altınok, S., 2004. Ankara koşullarında yem bezelyesi hatlarında yem ve tane verimleri. Tarım Bilimleri Dergisi, 19(4): 457-461.

Uslu, Ö.S., Gedik, O., Alhumedi, M., Alminfi, K., 2021. Kuraklık stresinin bazı yem bezelyesi (Pisum sativum L.) çeșitlerinin çimlenme ve fide gelișimi üzerine etkisi. Uluslararası Anadolu Ziraat Mühendisliği Bilimleri Dergisi, 3(2): 28-36.

Uzun, A., Gün, H., Açıkgöz, E., 2012. Farklı gelişme dönemlerinde biçilen bazı yem bezelyesi (Pisum sativum L.) çeşitlerinin ot, tohum ve ham protein verimlerinin belirlenmesi. Uludağ Üniversitesi Ziraat Fakültesi Dergisi, 26(1): 27-38.

Yağcioğlu, A., 2015. Ürün İşleme. Ege Üniversitesi Yayınları, Ziraat Fakültesi Yayın No: 517, Genişletilmiş 2. Bask1, Bornova-İzmir. 